\title{
Phylogenetic position and inter-relationships of the osmotrophic euglenids based on SSU rDNA data, with emphasis on the Rhabdomonadales (Euglenozoa)
}

\author{
1 Fakultät für Biologie, \\ Pflanzenmorphologie \\ und Feinbau der Zelle, \\ Universität Bielefeld, \\ Postfach 100 131, 33501 \\ Bielefeld, Germany \\ 2 Botanisches Institut, \\ Universität Köln, Gyrhofstr. \\ 15, 50931 Köln, Germany
}

\author{
A. Preisfeld, ${ }^{1}$ I. Busse, ${ }^{1}$ M. Klingberg, ${ }^{2}$ S. Talke ${ }^{1}$ and H. G. Ruppel ${ }^{1}$ \\ Author for correspondence: A. Preisfeld. Tel: +49 521106 5593. Fax: +49 5211066039. \\ e-mail: a.preisfeld@biologie.uni-bielefeld.de
}

\begin{abstract}
In order to reconstruct the evolution of euglenid flagellates, euglenozoan SSU rDNA data have been used to investigate phylogenetic relationships with a focus on osmotrophic taxa and especially on the Rhabdomonadales. The dataset consisting of the SSU rDNAs of osmotrophic, phagotrophic and phototrophic taxa was used in parsimony, maximum-likelihood and distance analyses. Five genera make up the Rhabdomonadales, all of them osmotrophic: Gyropaigne, Menoidium, Parmidium, Rhabdomonas and Rhabdospira. According to our analyses they form a strongly supported monophyletic assemblage which is characterized by a low sequence divergence compared to the euglenids in general. Closest relatives are the members of the osmotrophic genus Distigma. All primary osmotrophic species constitute a larger monophyletic group with the phototrophic euglenids and the phagotroph Peranema trichophorum. The combination of three rhabdomonadalian species Rhabdomonas gibba, Rhabdomonas spiralis and Rhabdospira spiralis with nearly identical SSU rDNA sequences is strongly recommended. The phagotroph Petalomonas cantuscygni branches at the bottom of the euglenid subtree with significantly weaker support. The inter-relationship of the three distinct euglenozoan taxa (euglenids, kinetoplastids and diplonemids) could not be convincingly resolved by this study.
\end{abstract}

Keywords: euglenids, molecular phylogeny, osmotrophs, Rhabdomonadales, SSU rDNA

\section{INTRODUCTION}

According to morphological resemblance (CavalierSmith, 1981; Kivic \& Walne, 1984) and to molecular data (Montegut-Felkner \& Triemer, 1997; Linton et al., 1999, 2000; Maslov et al., 1999; Preisfeld et al., 2000) euglenids and kinetoplastids have been placed in a supertaxon Euglenozoa (Cavalier-Smith, 1981). This was extended to include the genus Diplonema (Cavalier-Smith, 1993; Montegut-Felkner \& Triemer, 1994, 1996) and Postgaardi (Simpson, 1997). The Euglenozoa form a monophyletic group of flagellated

This paper was presented at the XIIIth meeting of the International Society for Evolutionary Protistology in České Budějovice, Czech Republic, 31 July-4 August 2000. cells whose systematic position still remains unclear. Based on SSU rRNA analyses they branch at the bottom of the Eukaryotes (Sogin et al., 1986, 1989; Vossbrinck et al., 1987; Sogin \& Silberman, 1998). However, Morin (2000) considers the early divergence of the Euglenozoa in a eukaryotic SSU rDNA tree as a long branch attraction due to an accelerated rate of evolution. Incongruencies between SSU rDNA based trees and trees based on protein-coding genes like translation elongation factors $1 \alpha$ and 2 (Hashimoto et al., 1997), $\alpha$ - and $\beta$-tubulin (Keeling, 1998) show that the phylogenetic position of the Euglenozoa among the eukaryotes is still controversial.

The euglenids are characterized by a pellicle structure built by an epiplasmic layer of proteins which underlies the plasma membrane. The pellicle structure is 
stabilized by microtubules as cytoskeletal elements (Kivic \& Walne, 1984). Euglenids undergo a closed mitosis with intranuclear spindle, and retain an intact nuclear envelope and nucleolus during division (Triemer \& Farmer, 1991). It is thought that a phagotrophic euglenid has engulfed a green alga or its chloroplast and developed a plastid with three surrounding membranes to create the phototrophic euglenids (Gibbs, 1978). The uptake of eukaryotic prey has to meet the requirements of a complex ingestion apparatus like the one in Peranema trichophorum. The flagella of the euglenids can either both be emergent or one can be reduced or completely absent, as in Petalomonas cantuscygni (Farmer \& Triemer, 1988). Emergent flagella of euglenids have a paraxonemal rod (PAR) and non-tubular mastigonemes (Willey et al., 1988). The carbohydrate storage is paramylon, a $\beta$-1,3-glucan (Kiss et al., 1987).

Recently published molecular data with the SSU rDNA (Montegut-Felkner \& Triemer, 1997; Linton et al., 1999, 2000; Preisfeld et al., 2000) support the monophyly of the Euglenozoa and of the sister clades kinetoplastids and euglenids. Maslov et al. (1999) who analysed two Diplonema SSU rDNA sequences and one COI sequence of Diplonema papillatum could not resolve the inter-relationships within the Euglenozoa.

The phototrophic species of the Euglenales, including the secondary osmotrophs Astasia longa and Khawkinea quartana, and the phototrophic Eutreptiales form a monophyletic assemblage with the phagotrophic taxon Peranema trichophorum (Heteronematales) as next relative (Montegut-Felkner \& Triemer, 1997; Linton et al., 1999, 2000; Preisfeld et al., 2000). At the molecular level, little is known about the phagotrophic and the osmotrophic euglenids. The lack of structures visible by light microscopy, such as plastids and ingestion devices, has led to confusing and inconsistent systematic positions and relations within the osmotrophs in general and the Rhabdomonadales in particular (Bourrelly \& Georges, 1951; Cann, 1986; Christen, 1958, 1963; Huber-Pestalozzi, 1955; Leedale, 1967; Leedale \& Hibberd, 1974; Pringsheim, 1936, 1942, 1963; Skuja, 1939, 1948, 1956). In this study we present the results of SSU rDNA data analysis with a focus on the position and interrelationship of the Rhabdomonadales, and reflect on possible evolutionary pathways.

\section{METHODS}

Culture conditions. Cultures were obtained from the Sammlung von Algenkulturen der Universität Göttingen (SAG), Germany, and The Culture Collection of Algae and Protozoa (CCAP), UK. Menoidium bibacillatum Pringsheim (SAG 1247-1), Menoidium cultellus Pringsheim (SAG 1247-2), Menoidium intermedium Pringsheim nom. nud. (SAG 1247-3), Parmidium scutulum (Skuja) Christen (SAG 232.80), Parmidium circulare Christen (SAG 230.80), Rhabdomonas spiralis Pringsheim (SAG 233.80), Rhabdomonas costata (Korshikow) Pringsheim (SAG 236.80),
Rhabdomonas gibba (Skuja) Pringsheim nom. nud. (SAG 1271-2), $R$. incurva (Fresenius) Klebs (SAG 235.80), Rhabdomonas intermedia Christen (SAG 238.80) and Rhabdospira spiralis Pringsheim (CCAP 1271/5), were grown in soil water medium $3 \mathrm{c}$ at $20^{\circ} \mathrm{C}$ in the dark (accession numbers are shown on the figures). Eutreptia viridis Perty (SAG 1226-1c) AF157312 was cultivated under a 14:10 h light:dark photoperiod in brackish water medium 6 and Lepocinclis ovum (Ehrenberg) Lemmermann (SAG 1244-8) AF110419 in medium 3b (all media: Schlösser, 1994).

Taxa included in the analyses. Euglenid sequences included in this analysis: Astasia longa AF112871, Colacium vesiculosum AF081592, Distigma curvatum AF099081, Distigma proteus AF106036, Euglena acus AF090871, Euglena agilis AF115279, Euglena anabaena AF081593, Euglena gracilis M12677, Euglena oxyuris AF090869, Euglena spirogyra AF150935, Euglena stellata AF150936, Euglena viridis AF090868, Eutreptia pertyi AF081589, Eutreptiella gymnastica AF081590, Eutreptiella sp. AF112875, Gyropaigne lefevrei AF110418, Khawkinea quartana U84732, Lepocinclis buetschlii AF096993, Lepocinclis ovata AF061338, Peranema trichophorum U84733, U84734, Petalomonas cantuscygni U84731, Phacus megalopsis AF090870, Phacus pleuronectes AF081591, Phacus pyrum M12677, Phacus smulkowskianus (Zakrys) Kusber, comb. nova 1998, AF119118 (formerly named Phacus similis), Strombomonas sp. AF096994, Trachelomonas hispida AF090377, Trachelomonas volvocina AF096995. Kinetoplastid sequences: Trypanosoma brucei M12676, Leishmania tarentolae X53916, Crithidia fasciculata Y00055, Bodo caudatus X53910, Cryptobia bullocki AF080224. Diplonemid sequences: Diplonema papillatum AF119811, Diplonema sp. AF119812. Outgroup sequences: Arxiozyma telluris (Fungi) Y15849, Chilomonas paramecium (Cryptophyta) L28811, Dictyostelium discoideum (Dictyosteliida) K02641, Marchantia polymorpha (Viridiplantae) X75521, Paramecium tetraurelia (Alveolata) X03772, Physarum polycephalum (Myxomycetes) X13160, Proteromonas lacertae (Stramenopiles) U37108, Saccharomyces cerevisiae (Fungi) J01353, M27607.

DNA isolation, amplification and sequencing. Isolation of DNA, amplification and sequencing of SSU rDNA was performed as described elsewhere (Preisfeld et al., 2000). Briefly, oligonucleotides specific to conserved regions of eukaryotic SSU rDNA were used as primers for PCR with REDTaq DNA polymerase (Sigma) as reaction enzyme. The SSU rRNA gene was purified by E.Z.N.A. Cycle Pure Kit (Peqlab) and subsequently cloned in Escherichia coli Top $10 \mathrm{~F}^{\prime}$ using TOPO TA Cloning Kit (Invitrogen) following manufacturers' instructions. Isolation of plasmids was performed with E.Z.N.A. Plasmid Miniprep Kit II (Peqlab). Resulting plasmids were sequenced via primer walking using both strands of the SSU rDNA (Ready Reaction dRhodamine Terminator Cycle Sequencing Kit; Applied Biosystems Perkin-Elmer) according to the manufacturer's protocol with M13 uni, M13 reverse, and internal oligonucleotides as sequencing primers.

Sequence alignment. Euglenid sequences were aligned to available sequences of euglenozoan and outgroup organisms. A preliminary alignment was performed using CLUSTAL X (Thompson et al., 1997), with gap opening penalty 10 , gap-extension penalty $0 \cdot 5$, and DNA weight matrix IUB (Preisfeld et al., 2000). It was necessary to correct the alignments manually by means of secondary structure based on the models of Euglena gracilis, Petalo- 
monas cantuscygni, Peranema trichophorum, Khawkinea quartana, Bodo caudatus, Trypanosoma brucei and Saccharomyces cerevisiae SSU rRNA obtained from the rRNA web server (Van de Peer et al., 2000) with the help of GeneDoc (Nicholas \& Nicholas, 1997). Non-homologous regions were excluded prior to final analyses. Because of the unusually long genes of the osmotrophs and the high sequence divergence within euglenozoan taxa, several alignments had to be produced for different aims of tree inferences.

Phylogenetic analysis of SSU rDNA data. Maximum-parsimony and maximum-likelihood analyses were performed using PAUP* (version 4.0b4a; Swofford, 1998) with a heuristic search (gaps are treated as missing; addseq = random; $\operatorname{nreps}_{[\text {parsimony }]}=25 ; \operatorname{nreps}_{[\text {likelihood }]}=5$ ). Distance analysis and neighbour-joining tree construction were performed with TREECON 1.3b (Van de Peer \& De Wachter, 1994).

Decay support (Bremer, 1994) for monophyletic groups found in parsimony analyses was determined with PAUP* using the clade constraint method described by Morgan (1997). Non-parametrical bootstrapping was performed, generating 1000 pseudoreplicates, to obtain a statistical measure for tree robustness (Felsenstein, 1985). The sequence divergence was calculated by dividing the observed number of differences by the number of aligned sequence positions.

\section{RESULTS}

\section{General tree topology and position of the Rhabdomonadales}

In order to gain information on the general grouping of euglenid taxa, and especially on the position of the taxon Rhabdomonadales, the euglenozoan dataset, in which all published and newly sequenced euglenid SSU rDNA sequences are included, has been analysed using maximum-parsimony, maximum-likelihood and distance methods. The resulting tree is drawn schematically to facilitate the recognition of all major monophyletic assemblages (Fig. 1). The alignment used to infer this tree had to be reduced drastically to 984 unambiguously homologous positions according to secondary structures. The Rhabdomonadales form a well-supported monophyletic assemblage with a close relationship to members of the genus Distigma which represents a paraphyletic taxon. The resulting clade comprises all members of the ancestrally osmotrophic euglenids, which form a monophyletic group with the phagotrophic Peranema trichophorum (Heteronematales) and the monophyletic phototrophs. The support for the sister group relationship of Peranema trichophorum and the phototrophs could not be confirmed by maximum-parsimony analysis with the result that the sister group of the osmotrophs cannot be identified unambiguously. Within the phototrophic euglenids, the Euglenales form a wellsupported clade the bootstrap support for which increases to $93 \%$ when the highly derived sequence of Euglena mutabilis is omitted. The phototrophic Eutreptiales branch at the bottom of the phototrophic clade, their monophyly being weakly supported. The phagotroph Petalomonas cantuscygni, a member of the Sphenomonadales, is located at the base of the euglenids. This species is separated by a long branch from all other euglenids included in our analyses. The two Diplonema species form a monophyletic clade within the euglenozoan radiation. The relationship between euglenids, diplonemids and kinetoplastids could not be unambiguously resolved. Either diplonemids and euglenids form a monophyletic group (maximum-likelihood analysis) or diplonemids cluster together with kinetoplastids (maximum-parsimony and distance analyses). The kinetoplastids comprising bodonids and trypanosomatids form a well-supported monophyletic group which is separated by a long branch from the diplonemids and euglenids.

\section{Sequence divergence}

A possible explanation for the weak support of some of the internal nodes can be found in high pairwise sequence divergences (Fig. 2) derived from an uncorrected distance matrix. There is a high genetic diversity of the euglenid SSU rDNA compared to the kinetoplastids. The Diplonema sequences are very similar to each other but very different when compared with the euglenids and the kinetoplastids, reflecting their unstable position. The Rhabdomonadales form a homogeneous taxon with low sequence divergences. Adding the other osmotrophic genus Distigma to the Rhabdomonadales results in a higher sequence divergence comparable to the phototrophs.

\section{Tree inference of the osmotrophic euglenids}

After the general position of the Rhabdomonadales within the euglenids was resolved, it became obvious that the chosen alignment gave no proper resolution of the relationship within the clade under study. Therefore a second alignment comprising only the osmotrophic taxa was produced to include more homologous positions. The aim was to find the basal members of the Rhabdomonadales to get more information about the relationships within this clade. Distigma proteus and Distigma curvatum, the closest relatives in the previous analyses (Fig. 2), were used to root a maximum-parsimony tree (Fig. 3). The genus Parmidium forms a highly supported monophyletic clade that is the sister group to the remaining taxa of the Rhabdomonadales, leading to a non-resolved more weakly supported cluster of the genera Rhabdomonas, Menoidium and Gyropaigne.

\section{Inter-relationship of the Rhabdomonadales}

The following analyses were based on an alignment with only the Rhabdomonadales sequences. Numerous positions which can only be homologized within this clade could be interpreted as molecular autapomorphies of this homogeneous taxon. The omission of the Distigma sequences allowed the inclusion of additional 600 general and 65 parsimony informative characters and offered a well-supported resolution of 


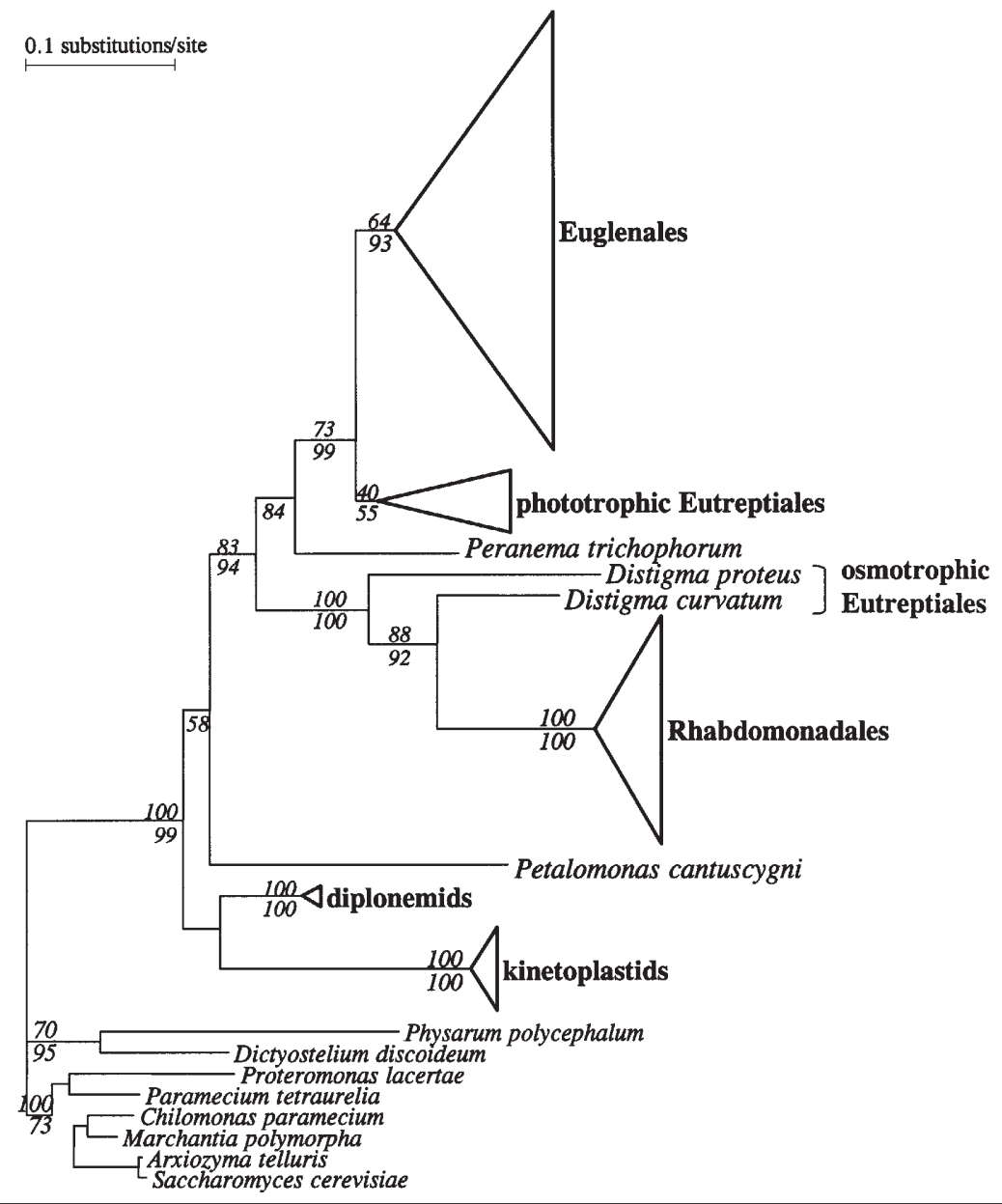

Fig. 1. Euglenozoan maximum-likelihood tree (Hasegawa et al., 1985) of SSU rDNA. Bootstrap values for maximum-parsimony analysis above; for neighbour-joining (Kimura, 1980) below branches. Consensus of 1000 bootstrap replicates. General tree topology was independent of the evolutionary model used.

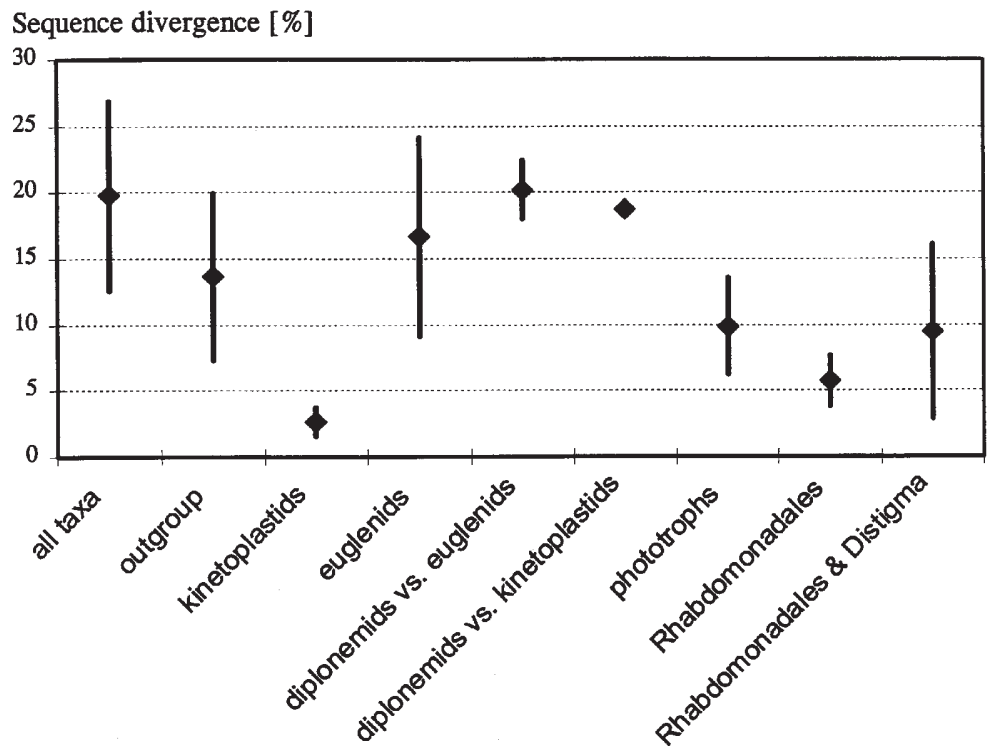

Fig. 2. Sequence divergences as mean values and standard deviation of taxa joined in the analysis. Same dataset as in Fig. 1.

all Rhabdomonadales (Fig. 4). Parmidium as root within this clade is supported by high bootstrap values and decay indices. At first sight it is evident that Rhabdomonas is a paraphyletic taxon. Rhabdomonas intermedia branches next to the genus Parmidium at the bottom of the Rhabdomonadales, giving rise to two sister clades. One includes Rhabdomonas costata, Rhabdomonas incurva (type species) and Gyropaigne lefevrei. The other one forms a larger monophylum with Rhabdospira spiralis, Rhabdomonas gibba and 


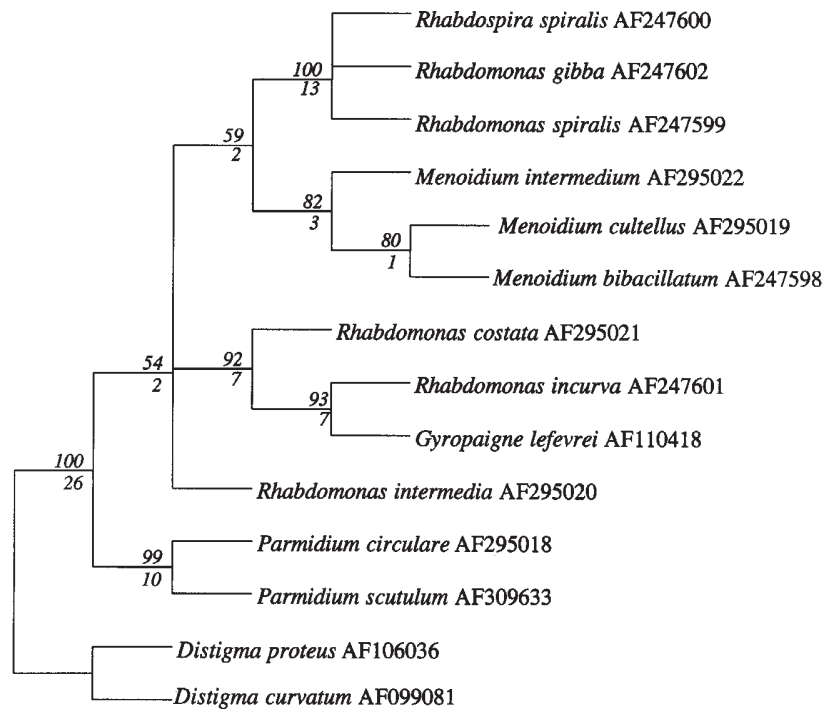

Fig. 3. Maximum-parsimony tree of SSU rDNA of the primary osmotrophic taxa of euglenids. Most parsimonious tree: 791 steps, 1224 characters, 751 constant and 227 informative characters. Numbers above branches, bootstrap values; numbers below branches, decay indices. Consensus of 1000 bootstrap replicates.

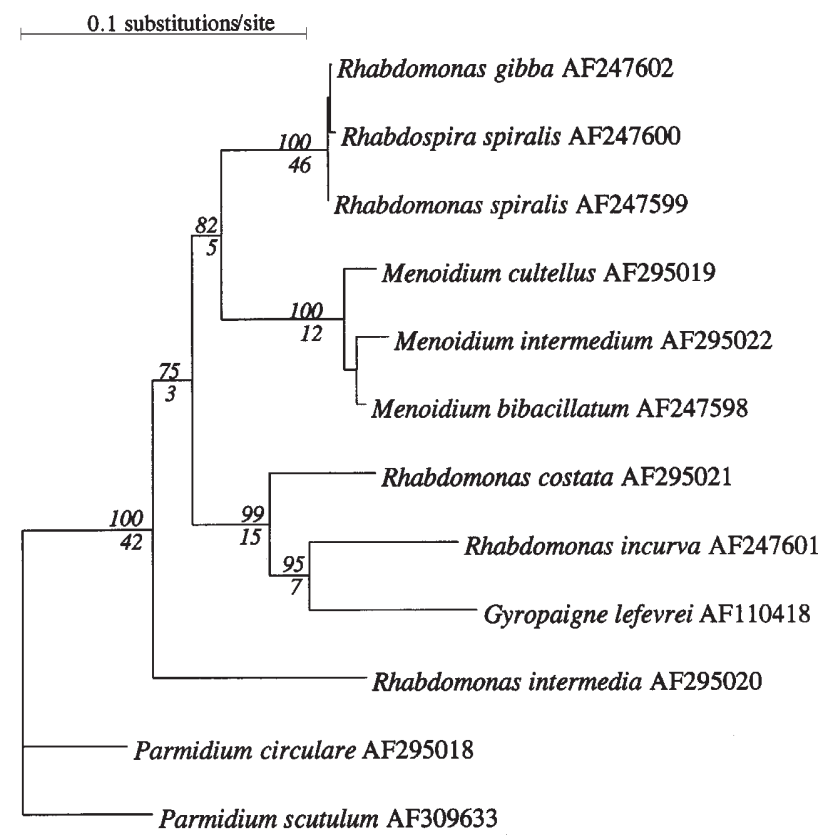

Fig. 4. Maximum-likelihood tree (Hasegawa et al., 1985) of SSU rDNA of the Rhabdomonadales. Maximum-parsimony (843 steps, 1805 characters, 1232 constant and 291 informative characters), bootstraps above branches. Distance bootstraps below branches. Consensus of 1000 bootstrap replicates.

Rhabdomonas spiralis, as the sister clade of the genus Menoidium. Although only 1173 nucleotides of $M$. intermedium have been sequenced, the monophyly of this clade can be considered to be well supported with a bootstrap value of 100 and a decay index of 12 . When $M$. intermedium was excluded from the analysis, the decay index for the monophyly of the genus Menoidium increased to 52 (data not shown), but the decay indices of all other nodes remained stable. It is important to mention that the sequences of Rhabdospira spiralis, Rhabdomonas spiralis and Rhabdomonas gibba are identical with less than $1 \%$ difference in their base pairs, a very unusual phenomenon in this highly divergent group of protists.

\section{How do molecular and morphological data fit together?}

In an attempt to combine our molecular data with morphological characters, the autapomorphies of major clades in the Rhabdomonadales have been mapped onto a bootstrapped maximum-parsimony tree of the Rhabdomonadales (Fig. 5). Our molecular data correspond well with morphological data. The monophyly of the Rhabdomonadales can be justified by the scroll, a structure which is built by a sheath of microtubules and amorphous material surrounding the canal (Leedale \& Hibberd, 1974; Cann, 1986). Ultrastructural investigations show that the scroll is not present in other euglenid organisms and especially not in Distigma species (Yamaguchi \& Anderson, 1994; Angeler, 1999). Beyond that, they can be identified easily by the fusion of pellicular ridges and grooves, and the reduction of the ventral flagellum. Parmidium can be separated from Rhabdomonas, Menoidium and Gyropaigne by the deep indentations of the cell body. The development of prominent keels can be found in one monophyletic group that includes Gyropaigne lefevrei. The other clade comprises organisms with flattened cell bodies and diverges as a group in which the posterior end is twisted. Rhabdomonas gibba, Rhabdomonas spiralis and Rhabdospira spiralis are almost identical in their SSU rDNA sequences and likewise in their morphology. The lineage of Menoidium includes extremely flattened cells with elongated anterior and posterior ends (Leedale, 1967, and references therein).

\section{DISCUSSION}

\section{Phylogenetic position of major Euglenozoa clades}

Phylogenetic analyses of SSU rDNA sequences of the euglenids are consistent with the existing hypotheses concerning their evolution: phagotrophs arose prior to phototrophs (Montegut-Felkner \& Triemer, 1997; Linton et al., 1999, 2000; Preisfeld et al., 2000). Phototrophs evolved in a single event after an uptake of eukaryotic phototroph prey by a phagotrophic Peranema-like organism, followed by the evolution of plastids (Gibbs, 1978).

The phototrophs form a highly supported clade comprising two groups: firstly, the members of the 


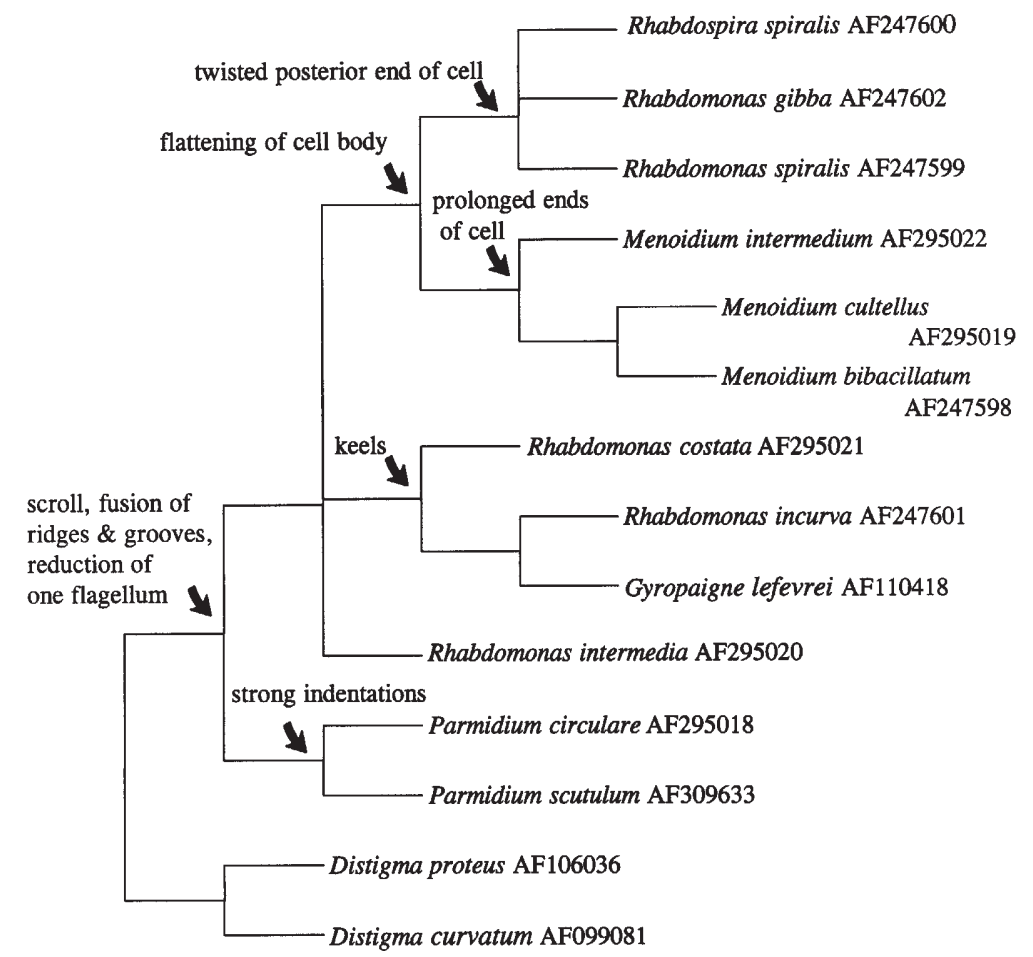

Fig. 5. Maximum-parsimony tree of SSU rDNA with mapped morphological autapomorphies of some clades.

well-founded clade Euglenales that share the synapomorphy of the reduced ventral flagellum, and secondly, the green Eutreptiales with two or more emergent flagella which we interpret as a plesiomorphic character. The molecular support for the Eutreptiales is correspondingly weak. In contrast to the Euglenales, which include osmotrophic taxa whose plastids have been lost (Khawkinea quartana, Astasia longa), no evidence for the former possession of plastids could be found for the osmotrophic Eutreptiales. Whereas the osmotrophic members of the Euglenales are placed within the same clade as the phototrophic Euglenales, molecular (Montegut-Felkner \& Triemer, 1997; Linton et al., 1999, 2000) and morphological (Leedale, 1967; Dawson \& Walne, 1994) data separate the osmotrophic members of the Eutreptiales from the phototrophic Eutreptiales (Preisfeld et al., 2000). The occurrence of the phototrophic members of the Eutreptiales in a clade together with all phototrophic euglenids and the divergence of the osmotrophic Eutreptiales in a major osmotrophic clade contradicts the validity of a taxon Eutreptiales comprising both phototrophs and osmotrophs.

The overall tree is heavily influenced by an unbalanced taxon sampling. Only two sequences from phagotrophic euglenids could be included in this analysis. The phylogenetic position of Petalomonas cantuscygni and Peranema trichophorum has therefore to be regarded with caution. This may also be the reason for the weak resolution at the base of the euglenozoan tree. We can confirm that the Euglenozoa comprise three major clades (euglenids, kinetoplastids and diplonemids), but the inter-relationship is not resolvable with the present taxon sampling.

\section{Phylogenetic position of the Rhabdomonadales and taxonomic implications}

Until now the only primary osmotrophic taxa whose SSU rDNA sequences had been studied (Preisfeld et al., 2000) were two Distigma species (Eutreptiales) and Gyropaigne (Rhabdomonadales). With the addition of 11 taxa of the Rhabdomonadales, an intensive study of this clade gives strong support for the monophyly in a major clade of osmotrophs with Distigma as next relatives. The homogeneity of the rhabdomonadalian SSU rDNA can also be corroborated by a comparison of their sequence divergence relative to those of other euglenids. The latter and the high support for the clade Rhabdomonadales in all tree inferences sustain the validity of this taxon that was erected by Leedale (1967) based on morphological characters.

Generally, the molecular analyses performed with the SSU rRNA gene in this study are in accordance with previous morphological and taxonomic investigations. The taxon Rhabdomonadales was erected by Leedale (1967) as an order with five genera: Gyropaigne, Menoidium, Rhabdomonas, Rhabdospira and Parmidium. He pointed out that all these taxa have one emergent flagellum which is flexible during locomotion throughout its length and stiff in stationary cells; have rigid pellicles; have osmotrophic nutrition; lack an ingestion apparatus; lack plastids, stigma and paraxial swellings. The scroll which surrounds the canal can be considered as autapomorphy of this clade (Leedale \& Hibberd, 1974). It is exclusively reported from species of this taxon (Leedale, 1967; Leedale \& Hibberd, 1974). Distigma, the next relative to the Rhabdomonadales, has two emergent flagella and a flexible 
pellicle. The reduction of one flagellum and a rigid pellicle accompanied by the fusion of the pellicle strips to a nearly continuous epiplasmic layer can be interpreted as autapomorphies of the Rhabdomonadales, but arose convergently at several points (i.e. Euglenales) in the evolution of the Euglenozoa (Leedale, 1978).

Further analysis, restricted to the osmotrophs and using an alignment that allows the inclusion of more informative characters, suggested that the root of the Rhabdomonadales is probably the genus Parmidium. Christen (1963) already suggested that this genus could have given rise to the other genera of the Rhabdomonadales according to the rounded cell shape of Parmidium that allows all cell-shape modifications having taken place in the other genera of the order. The monophyletic genus Parmidium can be distinguished morphologically by the ventral indentation and a shield-like cell body.

\section{The genus Rhabdomonas and taxonomic considerations}

The validity of the genus Rhabdomonas has been questioned since its erection by Fresenius (1858). Skuja never accepted this taxon because he saw many transitions between Rhabdomonas and Menoidium (Skuja, 1948). Our analyses suggest that Rhabdomonas cannot be considered as a monophyletic genus because it branches on several nodes of the trees. The most basal branch is Rhabdomonas intermedia. Another group consists of Rhabdospira spiralis, Rhabdomonas spiralis and Rhabdomonas gibba. The sequences of these taxa differ by less than $1 \%$. The taxonomic descriptions that can be found for these osmotrophs are confusing: Rhabdospira spiralis Pringsheim, which was treated as a valid taxon by Leedale (1967), seems never to have been described properly. This, and other references about Rhabdospira, quote Pringsheim (1963) who only suggested the new genus Rhabdospira, but never described it following the rules of any taxonomic Code. Something similar happened to Rhabdomonas gibba (Skuja) Pringsheim. No reference for a valid description could be found. This species was described as Menoidium gibbum Skuja (1939) and Pringsheim probably renamed this strain as Rhabdomonas gibba in the collection without presenting a formal description. Rhabdomonas spiralis was described by Pringsheim (1942). He pointed out the strong resemblance to Menoidium gibbum Skuja with a small difference in the degree of flattening of the cell body. Christen (1963) suggested to transfer Rhabdomonas spiralis to the genus Menoidium. According to taxonomic Codes (International Code of Zoological Nomenclature and International Code of Botanical Nomenclature) the first species name given is the one with priority. With this information and the results of the molecular analyses we recommend to label Rhabdomonas gibba (SAG 1271-2) and Rhabdospira spiralis (CCAP 1271/5) in the appropriate culture collections as Menoidium gibbum Skuja (1939), because no valid descriptions of these taxa exist. Menoidium gibbum would then be the sister taxon to the clade of Menoidium bibacillatum, Menoidium cultellus and Menoidium intermedium nom. nud. This genus is characterized by a strongly flattened cell body and elongated posterior ends, which in some cases can be slightly twisted.

The genus Rhabdomonas appears as another paraphyletic group in this analysis. Rhabdomonas costata and the type species Rhabdomonas incurva can be found intermingled with Gyropaigne lefevrei. Gyropaigne can be distinguished from the genus Rhabdomonas because it has a number of pronounced helical keels (Christen, 1960). There is a range of forms from none to slight to pronounced keels, for instance the species Rhabdomonas torta (Christen, 1963). As only one species of Gyropaigne has been analysed in this study, no changes in the taxonomy are recommended.

\section{ACKNOWLEDGEMENTS}

The authors wish to acknowledge financial support to A.P. and I. B. provided by the Deutsche Forschungsgemeinschaft (PR 624/2-1). Bodo Müller deserves warmest thanks for critically reading the manuscript and Kordula Puls-Fricke is thanked for excellent technical assistance.

\section{REFERENCES}

Angeler, D. (1999). Distigma proteus var. longicauda var. nov. - a new colourless euglenoid described from cultures. Arch Hydrobiol Suppl 127, 19-33.

Bourrelly, P. \& Georges, G. (1951). Un nouvel Euglénien incolore, Gyropaigne lefevrei. Bull Mus Hist Nat 2e Ser 23, 453-455.

Bremer, K. (1994). Branch support and tree stability. Cladistics 10, 295-304.

Cann, J. P. (1986). Ultrastructural observations of taxonomic importance on the euglenoid genera Gyropaigne Skuja, Parmidium Christen, and Rhabdospira Pringsheim (Euglenida: Rhabdomonadina). Arch Protistenkd 132, 395-401.

Cavalier-Smith, T. (1981). Eukaryote kingdoms: seven or nine? BioSystems 14, 461-481.

Cavalier-Smith, T. (1993). Kingdom protozoa and its 18 phyla. Microbiol Rev 57, 953-994.

Christen, H. R. (1958). Farblose Euglenalen aus dem Hypolimnion des Hausersees. Schweiz Z Hydrol 20, 141-176.

Christen, H. R. (1960). Gyropaigne Skuja, eine bemerkenswerte Gattung der farblosen Eugleninen. Beih Schweiz Forstver 30, 31-37.

Christen, H. R. (1963). Zur Taxonomie der farblosen Eugleninen. Nova Hedwigia 4, 437-464.

Dawson, N. S. \& Walne, P. L. (1994). Evolutionary trends in euglenoids. Arch Protistenkd 144, 221-225.

Farmer, M. A. \& Triemer, R. T. (1988). Flagellar systems in the euglenoid flagellates. Biosystems 21, 283-291.

Felsenstein, J. (1985). Confidence limits on phylogenies: approach using the bootstrap. Evolution 39, 783-791.

Fresenius, G. (1858). Beiträge zur Kenntnis mikroskopischer Organismen. Abhandlungen herausgegeben von der Senckenbergischen naturforschenden Gesellschaft 2, 211-245. 
Gibbs, S. P. (1978). The chloroplasts of Euglena may have evolved from symbiotic green algae. Can J Bot 56, 2883-2889.

Hasegawa, M., Kishino, H. \& Yano, T. (1985). Dating the human-ape split by a molecular clock of mitochondrial DNA. J Mol Evol 22, 160-174.

Hashimoto, T., Nakamura, Y., Kamaishi, T. \& Hasegawa, M. (1997). Early evolution of eukaryotes inferred from protein phylogenies of translation elongation factors 1 and 2. Arch Protistenkd 148, 287-295.

Huber-Pestalozzi, G. (1955). Das Phytoplankton des Süsswassers. 4. Teil. Stuttgart. E. Schweizerbartsche Verlagsbuchhandlung.

Keeling, P. J. (1998). A kingdom's progress: Archezoa and the origin of eukaryotes. BioEssays 20, 87-95.

Kimura, M. (1980). A simple model for estimating evolutionary rates of base substitutions through comparative studies of nucleotide sequences. J Mol Evol 16, 111-120.

Kiss, J. Z., Vasconcelos, A. C. \& Triemer, R. E. (1987). Structure of the euglenoid storage carbohydrate, paramylon. Am J Bot $\mathbf{7 4}$, 877-882.

Kivic, P. A. \& Walne, P. L. (1984). An evaluation of a possible phylogenetic relationship between the Euglenophyta and Kinetoplastida. Origins Life 13, 269-288.

Leedale, G. F. (1967). Euglenoid Flagellates. Englewood Cliffs, NJ : Prentice-Hall.

Leedale, G. F. (1978). Phylogenetic criteria in euglenoid flagellates. Biosystems 10, 183-187.

Leedale, G. F. \& Hibberd, D. J. (1974). Observations on the cytology and fine structure of the euglenoid genera Menoidium Perty and Rhabdomonas Fresenius. Arch Protistenkd 116 319-345.

Linton, E. W., Hittner, D., Lewandowski, C., Auld, T. \& Triemer, R. E. (1999). A molecular study of euglenid phylogeny using small subunit rDNA. J Eukaryot Microbiol 46, 217-223.

Linton, E. W., Nudelmann, M. A., Conforti, V. \& Triemer, R. E. (2000). A molecular analysis of the Euglenophytes using SSU rDNA. J Phycol 36, 740-746.

Maslov, D. A., Yasuhira, S. \& Simpson, L. (1999). Phylogenetic affinities of Diplonema within the Euglenozoa as inferred from the SSU rRNA gene and partial COI protein sequences. Protist 150, 33-42.

Montegut-Felkner, A. E. \& Triemer, R. E. (1994). Phylogeny of Diplonema ambulator (Larsen and Patterson). 1. Homologies of the flagellar apparatus. Eur J Protistol 30, 227-237.

Montegut-Felkner, A. E. \& Triemer, R. E. (1996). Phylogeny of Diplonema ambulator (Larsen and Patterson). 2. Homologies of the feeding apparatus. Eur J Protistol 32, 64-76.

Montegut-Felkner, A. E. \& Triemer, R. E. (1997). Phylogenetic relationships of selected euglenoid genera based on morphological and molecular data. J Phycol 33, 512-519.

Morgan, D. R. (1997). Decay analysis of large sets of phylogenetic data. Taxon 46, 509-517.

Morin, L. (2000). Long branch attraction effects and the status of "basal eukaryotes": phylogeny and structural analysis of the ribosomal RNA gene cluster of the free-living diplomonad Trepomonas agilis. J Eukaryot Microbiol 47, 167-177.

Nicholas, K. B. \& Nicholas, H. B. G. (1997). Genedoc: a tool for editing and annotating multiple sequence alignment. http:// www.psc.edu/biomed/genedoc/.

Preisfeld, A., Berger, S., Busse, I., Liller, S. \& Ruppel, H. G. (2000).
Phylogenetic analyses of various euglenid taxa (Euglenozoa) based on 18S rDNA sequence data. J Phycol 36, 220-226.

Pringsheim, E. G. (1936). Zur Kenntnis saprotropher Algen und Flagellaten. 1. Mitteilung. Über Anhäufungskulturen polysaprober Flagellaten. Arch Protistenkd 87, 43-96.

Pringsheim, E. G. (1942). Contributions to our knowledge of saprotrophic algae and flagellata. III. Astasia, Distigma, Menoidium and Rhabdomonas. New Phytol 41, 171-205.

Pringsheim, E. G. (1963). Farblose Algen. Stuttgart: Gustav Fischer.

Schlösser, U. G. (1994). SAG-Sammlung von Algenkulturen at the University of Göttingen, Catalogue of Strains. Bot Acta 107, 113-186.

Simpson, A. G. B. (1997). The identity and composition of the Euglenozoa. Arch Protistenkd 148, 318-328.

Skuja, H. (1939). Beitrag zur Algenflora Lettlands II. Acta Hort Bot Univ Latv 11/12, 41-169.

Skuja, H. (1948). Taxonomie des Phytoplanktons einiger Seen in Uppland, Schweden. Symb Bot Ups 9, 1-399.

Skuja, H. (1956). Taxonomische und Biologische Studien über das Phytoplankton schwedischer Binnengewässer. Nova Acta $R$ Soc Sc Upsaliensis 16, 3-401.

Sogin, M. L. \& Silberman, J. D. (1998). Evolution of the protists and protistan parasites from the perspective of molecular systematics. Int $J$ Parasitol 28, 11-20.

Sogin, M. L., Elwood, H. J. \& Gunderson, J. H. (1986). Evolutionary diversity of eukaryotic small-subunit rRNA genes. Proc Natl Acad Sci US A 83, 1383-1387.

Sogin, M. L., Edman, U. \& Elwood, H. J. (1989). A single kingdom of eukaryotes. In The Hierarchy of Life, pp. 133-143. Edited by B. Fernholm, K. Bremer \& H. Jörnvall. Amsterdam: Elsevier.

Swofford, D. L. (1998). PAUP*. Phylogenetic Analysis Using Parsimony (*and Other Methods). Version 4a. Sunderland, MA: Sinauer Associates.

Thompson, J. D., Gibson, T. J., Plewniak, F., Jeanmougin, F. \& Higgins, D. G. (1997). The CLUSTAL_X Windows interface: flexible strategies for multiple sequence alignment aided by quality analysis tool. Nucleic Acids Res 24, 4876-4882.

Triemer, R. E. \& Farmer, M. A. (1991). An ultrastructural comparison of the mitotic apparatus, feeding apparatus, flagellar apparatus and cytoskeleton in euglenoids and kinetoplastids. Protoplasma 164, 91-104.

Van de Peer, Y. \& De Wachter, R. (1994). TREECON for Windows: a software package for the construction and drawing of evolutionary trees for the Microsoft Windows environment. Comput Appl Biosci 10, 569-570.

Van de Peer, Y., De Rijk, P., Wuyts, J., Winkelmans, T. \& De Wachter, R. (2000). The European Small Subunit Ribosomal RNA database. Nucleic Acids Res 28, 175-176.

Vossbrinck, C. R., Maddox, J. V., Friedman, S., DebrunnerVossbrinck, B. A. \& Woese, C. R. (1987). Ribosomal RNA sequence suggests microsporidia are extremely ancient eukaryotes. Nature 326, 411-414.

Willey, R. L., Walne, P. L. \& Kivic, P. (1988). Phagotrophy and the origin of the euglenoid flagellates. CRC Crit Rev Plant Sci 7 , 303-340.

Yamaguchi, T. \& Anderson, O. R. (1994). Fine structure of laboratory cultured Distigma proteus and cytochemical localization of acid phosphatase. J Morphol 219, 89-99. 